
$\$$ Research Square
Preprints are preliminary reports that have not undergone peer review.
They should not be considered conclusive, used to inform clinical practice, or referenced by the media as validated information.

\title{
A conceptual framework for integrated management of Post-Natural Disasters Recovery (PNDR) projects
}

\section{Homa Bahmani}

Huazhong University of Science and Technology - Main Campus: Huazhong University of Science and Technology

Wei Zhang ( $\square$ zhang_wei98@hust.edu.cn )

Huazhong University of Science and Technology - Main Campus: Huazhong University of Science and Technology https://orcid.org/0000-0002-2372-3776

\section{Research Article}

Keywords: Post-Natural disaster recovery, Post-Natural disaster reconstruction, Life-cycle, Project management.

Posted Date: June 2nd, 2021

DOI: https://doi.org/10.21203/rs.3.rs-161458/v1

License: (c) (1) This work is licensed under a Creative Commons Attribution 4.0 International License. Read Full License 


\section{Abstract}

Following the increasing rate of natural disasters, more attention is being paid to post-natural disaster reconstruction projects. However, from the perspective of project management, these projects show a significant degree of differences from the regular construction projects. Although some progress has been made on this topic, further research is needed to smooth pathways for the management of PostNatural Disaster Recovery (PNDR) projects. This paper provides a management framework for PNDR projects throughout the qualitative analysis of the research's selected resources. The resources identified by applying inclusion and exclusion criteria in academic online platforms have been coded by NVivo 2020, and corresponding groups have been made for PNDR life-cycle and project stages. An integrated management framework has been put forward throughout the simultaneous application of the research's suggested life-cycle and project stages for PNDR projects. The most significant observation of this study is the necessity of applying a continuous life-cycle to address projects' long-term goals and provide an experience-based database for the management of next natural disasters. The significant role of planning in the entire life-cycle of PNDR projects, recognition of the tasks that need to be handled continuously during entire PNDR projects, the necessity of simultaneous consideration of tangible and intangible recovery outcomes are the other findings of this study. Recognition of reconstruction as part of the bigger system, named recovery, also stressed the necessity of considering the recovery project as a whole.

\section{Introduction}

As witnessed in recent years, disasters that have escalated in frequency and severity can threaten human society's safety (Ismail et al. 2014; Vahanvati and Mulligan 2017; Hinzpeter and Sandholz 2018). Natural hazards have affected six million people in the Asia-Pacific region, and the death toll has risen to more than two million from 1970-2014 (Johnson, Depietri and, Breil 2016). According to the United Nations Office for Disaster Risk (UNISDR), the term "disaster" refers to a severe disruption of the functioning of a community or a society involving widespread human, material, economic or environmental losses, and impacts, which exceeds the ability of the affected community or society to cope using its resources' (CRED and UNISDR 2017; Etinay, Egbu and Murray 2018). Disaster is also the result of hazards being exposed to an insufficiently prepared society unable to manage its imminent impacts (Di Gregorio and Soares 2017). The main point to note is that the tremendous effects of disasters vary from injuries, deaths, and psychological disorders to building destruction, economic losses, and environmental damage (Di Gregorio and Soares 2017). Previous research showed that multilateral topics in PNDR projects involve countless stakeholders, triggering different demands, experiences, and knowledge (Ganapati and Mukherji 2014). The complexity of PNDR projects because of various beneficiaries and the dynamic environment requires proper answers. Although increased attention has been paid to the concept of "Post-Natural Disaster Recovery" (PNDR), many PNDR projects still cannot fully satisfy stakeholders' needs. In accordance with the traditional definition of projects, especially construction projects, a linear life-cycle has been mostly used in most PNDR projects. This short-term and not continuous life-cycle that 
neglects long-term development is a demanding challenge and needs to be solved. Figure 1 shows the prevalent definition of the life-cycle of PNDR projects schematically. A large body of evidence alongside Fig. 1. reveal that lesson learned which have been collected throughout the PNDR project will not be used as gained experience to prepare communities for next natural disasters.

To address the development objectives, step-by-step plans are necessary. Throughout the application of such detailed planning, the complexity of PNDR projects can also be settled properly, and simultaneously, the long-term recovery objectives can be reached. To provide management pathways to address these challenges, prevalent activities in PNDR projects should be identified, categorised, and followed at an appropriate time. Proposing a continuous life-cycle of PNDR projects and establishing project stages have been identified as a practical solution in this study. In accordance with the necessity of continuous development after a natural disaster and the need to identify a management framework for PNDR projects, this paper introduces a basic framework used to develop a strategy to manage PNDR projects based on the PNDR project management steps and its life-cycle.

\section{Methods}

A combination of methods has been applied to reach the research's goals. Figure 2 demonstrates how the methods function.

- Keyword-based literature review. The research commences with searching for reliable and relevant academic resources. The resources include theoretical and empirical findings related to Post-Natural Disaster Recovery projects. The resources have been chosen from thousands of electronic academic resources available at the time of this research. The researchers found the resources throughout such academic websites as Science Direct, Scopus, ProQuest, and Springer. Post-Natural Disaster Recovery, post-disaster reconstruction, and natural disasters were the keywords that have been used to refine the results. On the other hand, due to the significant number of short-listed resources and the researchers' limited time, the resources have been excluded from the research's scope based on the following criteria.

1. Other publications that are not academic (e.g., news articles).

2. Publications that are not written in English.

3. Publications before 2002.

4. After an initial review, articles can be excluded based on bias and methodological inconsistencies.

Finally, 125 resources have been chosen, and Mendeley has been utilised as the research's documentation system.

- Codification: In accordance with the multidimensional nature of PNDR projects covering various topics, throughout the application of NVivo 2020, a codification of the research's library has been done. These codes are roadmaps to create two sets of categorisations based on "Projects 
management stages" and "Project management life-cycle" and attempt to fairly consider the activities and their different required duration.

- Qualitative analysis. The analysis of the findings was done using qualitative methods. The qualitative approach presents a broad narrative of the findings from the selected resources. The conceptual framework for managing PNDR projects in this paper is based on generalisation and the authors' interpretation of those codes.

\section{Discussion}

The following sections present the results of our systematic review of the literature on the management of PNDR projects. The first section draws a summarised perspective of project management steps in post-natural disaster reconstruction projects. In accordance with the previous studies, the drawn factors have been placed in four stages. The second part will delve into presenting a life-cycle for PNDR projects. Based on the research's library, the term "reconstruction" has been changed to "recovery" to avoid PNDR projects' oversimplification. A combination of what has been discussed previously is presented in the last section by proposing a conceptual framework for the integrated management of PNDR projects.

\subsection{Project management stages}

Projects are usually assessed throughout the completion of the deliverable outcomes. These outcomes are suggested to be evaluated at the end of each phase. Additionally, successful completion of the last phase's outcomes is permission to go through the next stage (Project Management Institute 2000). As was proposed by Hidayat and Egbu (2010); Silva (2010), post-disaster reconstruction projects have been divided into three stages; "Planning, design, and construction". The method applied in this research has similar performance using their methodology with some modifications. Due to the considerable role of procurement in the progress of post-disaster reconstruction, "procurement" has been set as the fourth stage. Figure 3 illustrates various topics explored based on the research literature, where the most critical components are highlighted.

\subsubsection{Planning}

Given the rising prevalence of natural disasters and their sudden and destructive effects, there is an essential need to conduct comprehensive and detailed planning. Contrary to regular construction projects, time and budget limitation (Fayazi et al. 2017) and complexity and uncertainty (Ismail et al. 2014) in PNDR projects impose overwhelming pressure on the project team and government. Due to these dramatic differences, project life-cycle management plays a more crucial role in PNDR projects than common construction projects (Didem Gunes Yilmaz, Jason Von Meding 2013; Patel and Hastak 2013; Moatty 2017; Vahanvati and Mulligan 2017; Jinhua Han, Peng Zhang 2019). Focus on short-term activities (linear cycle) defined as PNDR projects life-cycle is problematic (Scott a. Supernaw 2019). Besides, continuous and long-term activities are supposed to bring sustainable outcomes. The necessity of the application of an integrated project management plan has also been mentioned by Ismail et al. 


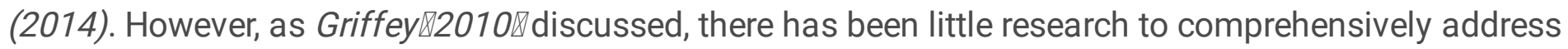
integrated and continuous planning in PNDR projects.

\subsubsection{Design}

Assuming the post-natural disaster reconstruction project as a system, including tangible and intangible members, designing all the features should comply with the system's characteristics. Furthermore, buildings as one of the tangible elements in PNDR projects should abide by integrated design. To provide a comprehensive understanding of the designing process in PNDR projects, this section explores a different attitude toward designing in "housing" and "infrastructures" (Hidayat and Egbu 2010).

- Housing, which has mostly been suggested to be planned before the disaster (Johnson 2006), spends almost 30-50 per cent of financial allocation on post-natural disaster reconstruction projects. This could be explained by the fact that one of the most prominent groups of stakeholders in PNDR projects is residents (Hidayat and Egbu 2010). High cost, lack of cultural suitability, unsatisfactory locations, low permanence, and negligence of poor people which can widen the poverty gap, have been ranked as frequent challenges in the housing reconstruction (Johnson 2006).

- Due to the infrastructures' role in revitalising the whole project, these facilities should bounce back to normalcy as soon as possible (Nejat and Ghosh 2016). Just after a natural disaster, an insufficient number of active infrastructures which is mostly the result of improper maintenance may cause troubles and delay is one of them (Dhamangaonkar 2019). There are a number of prerequisites that need to be achieved for a successful infrastructure designing: effective institutional management, well-defined coordination, well-established regulations, competent managers, effective consultation and communication with stakeholders, easy-to-use information management system, clearly identified goals, and adequate resource management have been identified as the most prominent ones (Ismail et al. 2014; Liu, Lin, and Wang 2014).

\subsubsection{Constriction}

Based on three primary objectives of construction projects, namely cost, time, and quality, the construction phase needs proper management to fairly balance these goals. Low quality of construction, especially the quality of materials and structures, may generate unsafe buildings, leading to an increment of vulnerabilities (Silva 2010; Ping Xu, Xiaoli Lu 2014; Ahmed and Charlesworth 2015; Cheng et al. 2017). Shortage of understanding of building standards, non-engineering structures and materials, and lack of supervision during construction are some of the most highly-ranked errors which can cause low quality in PNDR projects (Kopaei 2009; Zhao, Taucer and Rossetto 2009; Chang et al. 2011; Xu and Lu 2012; Didem Gunes Yilmaz, Jason Von Meding 2013; Platt 2018). According to the book published by Silva (2010), the construction phase has been decomposed into "housing and "infrastructures" from the perspective of "construction methods" and " construction technologies".

- While managers are trying to find an appropriate design based on what has been discussed later, selecting a proper housing method should also be contemplated. Identification of housing approach in each project depends on cost limitations, the importance of physical and social safety, 
revitalisation of livelihood, and community's goals (Enshassi et al. 2017). Housing approaches can generally be divided into three categories: Owner-Driven reconstruction, Donor-Driven reconstruction, and Contractor-Driven reconstruction (Johnson and Lizarralde 2012; Ganapati and Mukherji 2014; Scott a. Supernaw 2019). These approaches are also part of policy strategies known as "Top-down" and "Bottom-up" strategies and have different strengths and weaknesses.

- Although structure failures frequently happen in many construction projects, post-natural disaster reconstruction projects are more vulnerable to structure failures because of time limitations, affecting structural planning. Selection of proper construction methods depends on the hit area and local market's capacity to provide labour work and materials, availability of local materials, housing design, schedule, and availability of funding. Additionally, the possibility of either using traditional/vernacular methods or applying new and fast track construction technologies should be evaluated (Lizarralde 2004).

\subsubsection{Procurement}

As witnessed in reality, many PNDR projects face a lack of resources which is also mentioned as "supply chain dysfunction" or "inadequate procurement" (Chang et al. 2010; Enshassi et al. 2017; Fayazi et al. 2017; Scott a. Supernaw 2019). Shortage of reconstruction materials makes post-natural disaster reconstruction projects more susceptible to delays (Ismail et al. 2014; Scott a. Supernaw 2019). Uncertainties which are inseparable parts of post-natural disaster reconstruction projects, cause an escalation of the need to access resources. To broaden the perspective about sourcing, Chang et al. (2010) introduced factors affecting procurement in post-natural disaster reconstruction projects: legislations and policies, the construction industry, the construction market, and the transportation system. As Silva (2010) set sub-groups for the procurement, namely materials, logistics, and workmanship, the procurement has been categorised into the labour force, materials, and logistics.

- The labour force includes both contractors and workers. In the aftermath of a disaster when the demand for workmanship is dramatically increasing, the reconstruction quality is almost neglected. Indeed, apart from the matter of enough supply of labour force and contractors to expedite recovery speed (Kopaei 2009; Rouhanizadeh and Bergstrand, Sharareh Dhamangaonkar 2013; Kermanshachi, Bergstrand and Rouhanizadeh 2019), their competency should also be concentrated (Dhamangaonkar 2019).

- On the other hand, according to Chang et al. (2010), lack of resources, poor resource management, and doubtful material procurement are top reasons for PNDR projects' failure. Reconstruction materials should be chosen based on their resistance against future disasters, high quality, low cost, ability to be used instead of traditional material, and be in compliance with residents' life-style and architectural style of the hit area (Lizarralde 2004; Zhao, Taucer and Rossetto 2009; Johnson and Lizarralde 2012; Ahmed and Charlesworth 2015; Flores Salas 2016; Vahanvati and Mulligan 2017). Followingly, transportation, and logistics difficulties have been identified as one of the most challenging bottlenecks in post-natural disaster reconstruction project (Ismail et al. 2014; Flores Salas 2016; Celentano et al. 2019), as it has been proved that transportation has a direct impact on 
accessibility and price of materials (Chang et al. 2010). Especial attention has been paid to a fair distribution of materials among stakeholders overtime (Haghani and Afshar 2010). Especially in developing countries, it is necessary to provide different options for materials for the residents.

\subsection{Project management life-cycle}

There is a growing body of literature discussing Post-Natural Disaster Recovery projects' life-cycle. The importance of "Pre-disaster planning" and "Post-disaster planning" has been focused on by many scholars (Chen and Booth 2011; Rouhanizadeh and Bergstrand, Sharareh Dhamangaonkar 2013; Xu and Lu 2018). Present-day science indicates that PNDR projects have a complex nature which requires balancing pre-disaster preparedness and post-disaster relief. Wu (2003) stresses the necessity of continuity of the pre-disaster activities to the recovery phase and considers an integration phase to use disaster's window of opportunity to flourish potential chances. In a paper written by (Arain 2015), learning from the past, which has been called the "Proactive approach", may have impacts on pre-disaster planning and causes quick response after the disaster and can save time (Robert Olshansky 2002; Griffey 2010; Ismail et al. 2014). Within this lens, Chen and Booth (2011) proposed a model for the pre-disaster and post-disaster phase, consisting of preparation, prevention, and prediction for the pre-disaster planning phase and rescue, relief, and resettlement for the post-disaster recovery stage. Didem Gunes Yilmaz, Jason Von Meding (2013) succeeded in demonstrating the PNDR life-cycle as continuous steps including "Initial assessment, planning for a permanent solution, implementation and monitoring, and evaluation". Although this model has been drawn as a cycle, pre-disaster planning seems missing in this definition. A comprehensive life-cycle of PNDR projects has been summarised by (Dunford and Li 2011). It covers various topics starting from the beginning of the disaster to the development phase. In the last phase of this cycle which has been called the "Forgotten phase", not only restoration of structures in the medium and long-term period have been discussed; also social and economic well-being besides predisaster planning and increasing society capacity to cope with disasters have been focused on. Figure 4 represents a diagram to understand the continuous recovery life-cycle of natural-disasters.

\subsubsection{Pre-disaster stage}

Because of the unpredictable nature of natural disasters, disaster management strategies, especially preparation, should be considered an essential part of pre-disaster planning (Dikmen, Elias-Ozkan, and Davidson 2012). More recent work by Ping Xu, Xiaoli Lu (2014) shows that recovery needs previous plans to organise post-disaster activities. Additionally, Platt (2018); Xu and Lu (2018) suggest that disaster management's focus should be shifted from recovery-oriented to mitigation-oriented policies. Focusing on the advantages of establishing plans before a disaster, He and Zhuang (2016) declare that a predisaster investment of one dollar has about four dollars benefit in a post-disaster stage in case of an earthquake. However, effective pre-disaster planning heavily relies on the corporation of people and experts from different fields (Edgington 2011). Pre-disaster planning which has been called "up-front planning" (Johnson 2006) or "pre-planning phase" (Vahanvati and Mulligan 2017), has been focused by many scholars due to its worthwhile effects on time and cost management and clear task identification which provide an opportunity to take more advantages of the window of opportunity after the disaster 
(Wu 2003; Johnson 2006; Hidayat and Egbu 2010; Patel and Hastak 2013; Xu and Lu 2018; Dhamangaonkar 2019). Overall the results presented by Chen and Booth (2011) largely ignore overlaps in explanations of the pre-disaster stage and divided it into three phases, namely preparedness, prevention, and prediction. This issue has been considered by recent works Altay and lii (2006); Ping Xu, Xiaoli Lu (2014) and "Mitigation" and "Preparedness" have been chosen as a pre-disaster stage in this study. In the lens of sustainable recovery, preparation has been regarded as disaster mitigation and risk reduction strategy and is a vital prerequisite for maintaining sustainable development (Dikmen, Elias-Ozkan, and Davidson 2012; Ahmed and Charlesworth 2015). A number of categorisations have been proposed in the recent literature on mitigation measurements consisting of three categories, namely community protection works (dams, levees, and drainage systems), land-use practices, and building construction practices (Jordan 2012). Based on the previous research, Fig. 5 renders the most mentioned subjects that should be deemed in pre-disaster planning.

\subsubsection{Post-disaster stage}

There is ample evidence supporting the necessity of updating the pre-established post-disaster recovery plans after the disaster occurrence based on first-hand information (Griffey 2010; Silva 2010; Johnson and Lizarralde 2012; Rani et al. 2017; Platt 2018; Kermanshachi, Bergstrand and Rouhanizadeh 2019). The post-disaster recovery process differs from project to project due to numerous factors such as the severity of the disaster, physical damages, casualty numbers, existing trends before the disaster such as community social and economic conditions, recovery assistance programs, access to resources, geographic features, population, economic growth, and policies (Anuradha Mukherji 2008; Cheng et al. 2013; Ping Xu, Xiaoli Lu 2014; Lu and Xu 2015). Indeed, because of multiple stakeholders, this process should not be seen as a linear procedure; thus, a systematic formula can comprehensively answer the requirements and guarantee a resilient system against natural disasters (Guarnacci 2012; Jordan 2012).

Although Jordan (2012) believes that recovery does not have a fixed way and some steps may be omitted or overlapped in a project because of its unique features, in most of the read papers, post-disaster recovery consists of two parts; "Emergency response" and "Recovery phase" (Chen and Booth 2011; Han 2014; Akiyama 2019). On the other hand, recent researches have emphasised physical recovery and the well-being of social, mental, and economic conditions (Han 2014; Xiao et al. 2019). Within the same lens, a comprehensive post-disaster recovery consists of "soft recovery" and "hard recovery" (Lu and Xu 2015; Akiyama 2019). Soft recovery, which is also called non-structural recovery comprises standards and regulations established to tackle natural disasters. These regulations can be seen as land-use policies, risk analysis, insurance, and financial compensations. Obviously, hard recovery (structural recovery) includes architectural design and the creation of physical barriers against future disasters (Lu and Xu 2015).

Although, some previous research express recovery as a bounce back to normalcy which was prevalent before the disaster Platt (2018); Jordan (2012) believes that the term "recovery" is mostly oversimplified by defining it as turning to normality. Han (2014) emphasised the necessity of progressive development activities beyond the reconstruction project's completion by expressing that there is no specific ending 
time for disaster recovery. Meanwhile, concentrating on assisting local officials in integrating hazard mitigation into the recovery process is another topic expressed by Han (2014). Comparing these definitions of recovery, two phases for recovery are proposed; "Short-term recovery" and "long-term recovery". While the former deals with bounce back to the pre-existing situation before the disaster, the latter focuses on the development strategy to improve resilience, equity, and sustainability in societies (Anuradha Mukherji 2008; Jordan 2012; Ping Xu, Xiaoli Lu 2014). On the other hand, the recovery phase starts immediately after a disaster and shows considerable overlaps with the emergency phase (Liu, Lin, and Wang 2014; Platt 2018) and should be linked to development efforts (Anuradha Mukherji 2008). In this study, the emergency phase consists of all the activities starting just after a disaster such as rescue, sheltering, restoration of critical structures, and consideration of secondary hazards. These short-term activities can last for months. "Short-term recovery" has been counted as part of the "emergency" phase, while holistic development of a system has been categorised within the "recovery" stage. Additionally, there is irrefutable evidence suggesting that the term "recovery" is preferred instead of "reconstruction" because of the recent concerns about recovering multidimensionally (Akiyama 2019). Figure 6 is this research's proposed model for the post-disaster recovery phase and its steps.

- Housing and infrastructures recovery. In the aftermath of a disaster, the reestablishment of structures is firmly connected to enhancing the general well-being of the residents. As Cheng et al. (2013) expressed, reconstruction after a natural disaster has two sides: reconstruction of the facilities' destroyed and development. The latter topic has been discussed as a fundamental key for prevention and preparedness against future natural disasters by Hidayat and Egbu (2010). The recovery phase has also been divided into: "housing" and "infrastructures". Sheltering and temporary housing should be categorised in the emergency phase, while, permanent housing should be planned in the recovery stage (Fig. 7). Construction of memorial buildings (Ge, Gu, and Deng 2010)(Liu, Lin, and Wang 2014) and protections against natural disaster (Du et al. 2016)(Wu 2003)(Jordan 2012) are also part of structural recovery; however, as Jordan (2012) emphasised, residents' overconfidence owning to the protective structures should be appropriately managed.

- Management recovery: In the aftermath of a disaster, multitudinous topics that arise necessitate a management body's existence. Alongside strategic decision-makings (rules and legislation), management is an essential step to ensure the established rules' validity. Numerous factors have been placed in the management division. The activities that are supposed to be followed in this section are shown in Fig. 8.

- Social recovery (humanity): The evidence from the last two decades strongly supports the natural disasters' severe effects on both people's physical and mental situations (Liu and Han 2009; Ge, Gu, and Deng 2010; Opdyke 2017; Akiyama 2019). A study conducted by Liu and Han (2009) nominated prerequisites for successful social recovery in PNDR projects as stable institutions, the supply of human resources, and financial support. Moreover, family's income, health conditions, availability of 
education, personal fulfilment, and social conditions have been recognised as life satisfaction factors (Liao et al. 2019).

- Economic recovery. In general, recovery of livelihood (local business) after a disaster is the main concern of the researchers when it comes to economic reestablishment (Guo 2012; Di Gregorio and Soares 2017; Edgington 2017; Sadiqi, Trigunarsyah and Coffey 2017; Vahanvati and Mulligan 2017; Celentano et al. 2019; Harrowell and Özerdem 2019; He 2019; Xu et al. 2019). Within the same context, Han (2014) proposed "Sustainable Livelihood Analyzing" to boost a community's capabilities to cope with disasters. Davidson et al. (2007); Okamoto and Ishikawa (2013) regard restoration of the economy as a necessary step to have a thriving temporary town and also one of the reconstruction's objectives (Sadiqi, Trigunarsyah, and Coffey 2017). Economic recovery can be followed in three main divisions which have been shown in Fig. 9.

- Policy recovery. Not only can regulations established by governments affect PNDR projects, but also due to requirements of PNDR project, changes/ modifications in policies have been widely observed (Johnson 2006). Governments that generally oversee recovery after disasters are among the principal stakeholders and their relationship with local people should be effectively framed to avoid dissatisfaction. As He (2019) described, governments' decisions directly impact the success of recovery plans. The process of how policy recovery expands into different topics is observed in Fig. 10.

- Environmental recovery. Most of the current evidence reveals environmental damages as one of the challenging barriers on the way to a successful recovery of PNDR projects (Xu and Lu 2012). As has been discussed by Lizarralde (2004), PNDR projects should focus on ecological-friendly decisions and at the same time, attempt to restore the damaged environment. Environmental management (mitigation activities) has been suggested to continue after short-term recovery to become part of the development plan (Wu 2003). This was confirmed by Ge, Gu, and Deng (2010) who found that afforestation reduces the probability of landslides and multi-purpose reservoirs. Additionally, the construction of ecological infrastructure can effectively restore the damaged environment.

\subsubsection{Integration stage}

To locate the mentioned activities in the last sections in their appropriate place within PNDR projects' lifecycle, some activities can be grouped in both pre-disaster and post-disaster stages. These activities which should be continuously followed, have set an elastic phase named "Integration stage". Participation, communication, disaster vulnerability reduction, financial assistance for residents and industries, and the necessity of frequently updating the regulations based on people's needs have been grouped in this stage.

Disaster vulnerability reduction focuses on the holistic perspective considering all aspects of society from building structure, economy, livelihood, social well-fare, and environment to improve the PNDR process (Tran 2015) comprehensively. Within this lens, the PNDR project has often been seen as an opportunity to Build Back Better, boost productivity, and attract more investment (Silva 2010; Rose 2011; Siriwardhana et 
al. 2012; Ganapati and Mukherji 2014; Ping Xu, Xiaoli Lu 2014; Edgington 2017; Hu et al. 2018; Celentano et al. 2019; Fayazi, Yeh and Li 2019). Answering the fundamental requirements like projects' time and quality was defined as an ultimate target (Rouhanizadeh and Bergstrand, Sharareh Dhamangaonkar 2013; Platt 2018).

On the other hand, weak consultation with community members, lack of coordination among stakeholders, and lack of voluntary participation have been identified as common barriers in PNDR projects (Rouhanizadeh and Bergstrand, Sharareh Dhamangaonkar 2013; Kermanshachi and Rouhanizadeh 2018). Ping Xu, Xiaoli Lu (2014); Rani et al. (2017); Rehman et al. (2019) believe that participation of all different stakeholders from governments, academia, people, organisations, and so forth is necessary for a successful PNDR project. However, the shortage of experience in the management of people participations may create negative impacts such as delays and cost overruns (Celentano et al. 2019). Furthermore, establishing structures/ guidelines seems vital to avoid such challenges (Flores Salas 2016). Needless to say, effective communication which has been regarded as a success factor (Sadiqi, Trigunarsyah, and Coffey 2017) has a prominent role in the whole life-cycle of PNDR projects (Yang 2011); however, Jinhua Han, Peng Zhang (2019) stressed on the significant role of communication in emergency management. Effective communication between governments and residents which can be measured by public anxiety reduction and increment in public trust can lead to approved planning, improved disaster recovery especially in time and quality management, better information flow, and enhancement of cohesion among stakeholders (Olshansky 2006; Hidayat and Egbu 2010; Yang 2011; Rouhanizadeh and Bergstrand 2019b).

In accordance with the continuous life-cycle of PNDR projects, funding and allocating resources should be seen as an on-going procedure aiming at both short-term and long-term objectives; however, Kermanshachi, Bergstrand, and Rouhanizadeh (2019) recommended fund allocation should be determined before a disaster which implies the necessity of selecting beneficiaries before the occurrence of catastrophe. Moreover, the lack of long-term recovery and funding plans may obstruct the project's success (Dhamangaonkar 2019; Kermanshachi, Bergstrand and Rouhanizadeh 2019; Rouhanizadeh and Bergstrand 2019).

Talking about updated regulations, even though site selection planning should be done before the disaster (Johnson 2006; Ge, Gu and Deng 2010; Silva 2010; Guarnacci 2012), many projects postpone site selection until the disaster happens. However, land-use planning can continue to the recovery phase (Wu 2003; Ge, Gu and Deng 2010; Edgington 2011).

Additionally, one of the most demanding topics that need to be thought before a disaster is distinguishing criteria for deciding to repair or reconstruct buildings (Edgington 2011; Dikmen and Elias-Ozkan 2016; Moatty 2017). The establishment of these regulations should initiate before a disaster (Edgington 2011); however, they will be applied after the disaster. Furthermore, the detailed standards to determine retrofit or reconstruction are necessary, and experts should conduct buildings' damage inspection after the disaster (Kermanshachi and Rouhanizadeh 2018; Dhamangaonkar 2019). 


\subsection{A conceptual framework for the management of PNDR projects}

The results of this analysis are summarised in a conceptual framework that aims at the integration of project management phases and the continues definition of the PNDR project's life-cycle. The classification of keywords in the "emergency stage and the "recovery stage" has been shown in Fig. 11.

Based on the available data, it can be proposed that:

- According to the definition of project in Project Management Institute (2000), "a project is a temporary endeavour undertaken to create a unique product or service. Temporary means that every project has a definite beginning and a definite end," it is necessary to clarify ending and beginning of PNDR projects because of their difference to regular projects. Bouncing back to what has been destroyed in a few days may take several years. Furthermore, short-term recovery plans cannot address community needs. The concept of Build Back Better, which has been focused on in recent years also points to the necessity of the establishment of long-term plans. This paper's conceptual framework is based on Vahanvati and Mulligan's (2017) suggested life-cycle for PNDR projects. The results achieved surpass the earlier work in this area regarding the necessity of linking the development recovery to the mitigation and preparedness phases.

- Identification of project steps based on the definition suggested by Project Management Institute (2000) and stages of a post-disaster reconstruction project by Silva (2010) have been combined with the PNDR life-cycle. A comprehensive management framework covers recovery of structures and community well-being throughout this combination, considering social and economic aspects have been addressed. In the course of this work, it has been revealed that planning as the most prominent step is present in all phases of PNDR projects.

- This framework reveals that some activities cannot be placed in just one stage of the PNDR lifecycle. These activities which should be followed during the entire life-cycle of the project have been grouped in the "Integration phase" which is an elastic stage. Apparently, stakeholders' participation in the PNDR project can both happen in the mitigation and preparedness phase, while nobody can ignore the role of beneficiary involvement in the recovery stage. An effective communication system is also needed for the entire PNDR project.

- Interestingly, the recovery phase seems the most crowded stage based on the project management steps. This stage includes all the steps of the research's proposed classification of project management, namely planning, design, construction, and procurement. Restoration or reconstruction of damaged houses and infrastructures is supposed to be done here. Therefore, it is not unexpected to see that post-natural disaster reconstruction is just one part of the more significant concept named Post-Natural Disaster Recovery.

\section{Conclusion}

Due to the escalating occurrence rate of natural disasters in recent years and their cascading destructive impacts on communities, post-natural disaster recovery/ reconstruction projects are being focused more. 
Numerous stakeholders and high pressure in PNDR projects make them more susceptible to difficulties. These limitations and the complexity and unsteady nature of these projects, require intelligent planning to deal with reconstruction procedures. Management of PNDR projects considering the intricate nature and participation of sundry stakeholders needs a simplified pathway. This study tries to simplify the management procedure of PNDR projects through the identification of the prevalent activities and locate these tasks in suitable places based on PNDR projects' timelines. Each aspect of the study is discussed concerning the findings.

1. The PNDR project stages have been defined. Throughout the establishment of these stages, the achievement of the project's outcomes can be tracked easier. The extracted activities have been coded into four groups; planning, design, construction, procurement.

2. In accordance with the defined difficulties in PNDR projects, proposing a life-cycle that defines the beginning and ending points of PNDR projects seems vital. The life-cycle consists of three main stages, pre-disaster stage, post-disaster stage, and integration stage.

3. By having a clearly-defined perspective of the PNDR project's life-cycle and its stages, types of crucial activities for better management have been recognised and represented in the Fig. of the conceptual framework.

Significant findings of this study are the following:

- The continuous stages in this framework are expected to solve the loss of the experience and knowledge gained throughout PNDR projects to be at the ready for imminent natural disasters.

- Although revitalisation of the destroyed facilities and buildings greatly impacts the recovery of other damaged aspects, negligence of recovery of the intangible sides such as economy and environment may cause failure in the disaster recovery goals. A comprehensive recovery can be followed throughout the application of the research's proposed framework.

- The significance of planning has been proved. Planning is the main task that should be seen in the entire PNDR projects' life-cycle.

- Dividing the life-cycle of PNDR project into pre-disaster stage and post-disaster stage, some activities have been grouped in the "integration stage" which should be followed during the entire PNDR project.

- Finally, the recovery phase has been identified as the most crowded stage considering the number of assigned project stages. Post-natural disaster reconstruction has been shown to be part of the more significant cycle named Post-Natural Disaster Recovery.

\section{Declarations}

\section{Acknowledgements}

We would like to thank the National Key Technologies Research and Development Program of China (2017YFC0805500) and National Natural Science Foundation of China (51308240) for their support of 
this research. Any opinions, findings, and conclusions expressed in this material are those of the authors and do not necessarily reflect the views of the foundations. We also want to thank the experts who gave us the experience regarding PNDR projects.

\section{References}

Ahmed I, Charlesworth E. R (2015) An evaluation framework for assessing resilience of post-disaster housing. International Journal of Disaster Resilience in the Built Environment 6(3):300-312. doi: 10.1108/IJDRBE-11-2013-0042.

Akiyama H (2019) Who Rebuilds? Civil Society in Post-Disaster Recovery in China and Japan. Dissertation, George Mason University.

Altay N, lii G.G (2006) Interfaces with Other Disciplines OR / MS research in disaster operations management. European Journal of Operational Research 175 (December 2004):475-493. doi: 10.1016/j.ejor.2005.05.016.

Mukherji A (2008) Negotiating Housing Recovery: Why Some Communities Recovered While Others Struggled to Rebuild in Post-Earthquake Urban Kutch, India, Curr. Biol. University of California. Available at:

https://www.ncbi.nlm.nih.gov/pubmed/11516946\%0Ahttps://linkinghub.elsevier.com/retrieve/pii/S09609822(01)00369-

\%0Ahttps://www.sciencedirect.com/science/article/pii/S0960982201003694\%0Ahttps://ac.elscdn.com/S0960982201003694/1-s2.0-S0960982201003694-mai.

Arain F (2015) Knowledge-based Approach for Sustainable Disaster Management: Empowering Emergency Response Management Team. Procedia Engineering. Elsevier B.V. 118(2015):232-239. doi: 10.1016/j.proeng.2015.08.422.

Celentano G. et al (2019) A matter of speed: The impact of material choice in post-disaster reconstruction. International Journal of Disaster Risk Reduction. Elsevier Ltd 34 (March 2018):34-44. doi: 10.1016/j.ijdrr.2018.10.026.

Chang Y, Wilkinson S, Seville E, Potangaroa R (2010) Resourcing for a resilient post-disaster reconstruction environment. International Journal of Disaster Resilience in the Built Environment 1(1):6583. doi: 10.1108/17595901011026481.

Chang Y, Wilkinson S, Potangaroa R, Seville E (2011) Donor-driven resource procurement for post-disaster reconstruction: Constraints and actions. Habitat International 35(2):199-205. doi:

10.1016/j.habitatint.2010.08.003.

Chen Y, Booth D. C. (2011) The Wenchuan Earthquake of 2008 Anatomy of a Disaster. Zhurnal Eksperimental'noi i Teoreticheskoi Fiziki. doi: 10.1007/978-3-642-21159-1. 
Cheng M. Y, Chiu K.C, Hsieh, Y.M, Yang I.T, Chou J.Sh, Wu Y.W (2017) BIM integrated smart monitoring technique for building fire prevention and disaster relief. Automation in Construction. Elsevier 84(August):14-30. doi: 10.1016/j.autcon.2017.08.027.

Cheng Y, He Zh, Xie Y, Deng H (2013) Modeling of Urban Post-disaster Reconstruction Using Extended Cellular Automata. In: International Conference on Geo-Informatics in Resource Management and Sustainable Ecosystem. Wuhan, 86-97.

CRED and UNISDR (2017) Economic losses, poverty \& disasters 1998-2017, CRED UNISDR. Available at: http://www.albayan.ae.

Davidson C. H, Johnson C, Lizarralde G, Dikmen N, Sliwinski A (2007) Truths and myths about community participation in post-disaster housing projects. Habitat International 31(2007):100-115. doi: 10.1016/j.habitatint.2006.08.003.

Dhamangaonkar V (2019) Identification of Legal and Policy Barriers to Timely Post-Disaster Reconstruction and Strategy Development for Effective Recovery Processes in United States, ProQuest Dissertations and Theses. The University of Texas. doi: .1037//0033-2909.126.1.78.

Yilmaz1D.G, Meding V.J, Erk G.K. (2013) A theoretical approach to the design of a survey instrument in post-disaster reconstruction: Defining indicators for a human-based study in rural built-environment. International Journal of Architectural Research 7(3): 40-56. Available at: http://web.b.ebscohost.com.pucdechile.idm.oclc.org/ehost/detail/detail?vid=0\&sid=5946c3b9-c41743fb-b7f6-4e88a838c75a\%40pdc-vsessmgr05\&bdata $=J m x h b m c 9 Z X M m c 2 I 0 Z T 1$ laG9zdC1 saXZI\#AN=97632884\&db=asu.

Dikmen N, Tahira S.E.O (2016) Housing after disaster: A post occupancy evaluation of a reconstruction project. International Journal of Disaster Risk Reduction 19:167-178. doi: 10.1016/j.ijdrr.2016.08.020.

Dikmen, N, Tahira S.E.O and Davidson C (2012) Comparison Of Post-Disaster Housing Procurement Methods In Rural Areas Of Turkey. Open House International 37:28-39.

Du F, Okazaki K, Ochiai Ch, Kobayashi H (2016) Post-disaster building repair and retrofit in a disasterprone historical village in China: A case study in Shangli, Sichuan. International Journal of Disaster Risk Reduction. Elsevier 16 (June 2016):142-157. doi: 10.1016/j.ijdrr.2016.02.007.

Dunford M, Li L (2011) Earthquake reconstruction in Wenchuan: Assessing the state overall plan and addressing the "Forgotten phase". Applied Geography 998-1009. doi: 10.1016/j.apgeog.2011.01.001.

Edgington D. W (2011) Viewpoint: Reconstruction after natural disasters: The opportunities and constraints facing our cities. Town Planning Review. doi: 10.3828/tpr.2011.35.

Edgington D. W (2017) Building back better along the Sanriku coast of Tohoku, Japan: Five years after the "3/11" disaster. Town Planning Review. 615-638. doi: 10.3828/tpr.2017.38. 
Enshassi A, Chatat T, Meding V.J, Forino G (2017) Factors Influencing Post-disaster Reconstruction Project Management for Housing Provision in the Gaza Strip, Occupied Palestinian Territories. International Journal of Disaster Risk Science. 8(4):402-414. doi: 10.1007/s13753-017-0155-4.

Etinay N, Egbu C, Murray, V (2018) Building Urban Resilience for Disaster Risk Management and Disaster for Risk Reduction. Procedia Engineering. Elsevier B.V.575-582. doi: 10.1016/j.proeng.2018.01.074.

Fayazi M, Arefian F.F, Gharaati M, Johnson C, Lizarralde G, Davidson C (2017) Managing institutional fragmentation and time compression in post-disaster reconstruction - the case of Bam. International Journal of Disaster Risk Reduction 21(September 2016):340-349. doi: 10.1016/j.ijdrr.2017.01.012.

Fayazi M, Yeh E. T, Li F. (2019) Development and divergent post-disaster trajectories in a mountain village: Temporal dynamics of differentiation after the 2008 Wenchuan earthquake. World Development. Elsevier Ltd, 124, p. 104663. doi: 10.1016/j.worlddev.2019.104663.

Flores S.A (2016) Evaluation of the Use of Lightweight Concrete Panels for Post Disaster House Reconstruction Using Building Information Modelling, PQDT - UK \& Ireland. Dissertation. University of Manchester. Available at: http://proxy.library.vcu.edu/login? url=https://search.proquest.com/docview/2001176850?accountid=14780\%0Ahttp://vcu-almaprimo.hosted.exlibrisgroup.com/openurl/VCU/vcu_services_page?url_ver=Z39.882004\&rft_val_fmt=info:ofi/fmt:kev:mtx:dissertation\&genre=di.

Ganapati N. E, Mukherji A (2014) Out of Sync: World bank funding for housing recovery, post-disaster planning, and participation. Natural Hazards Review 15(1):58-73. doi: 10.1061/(asce)nh.15276996.0000120.

Ge Y, Gu Y, Deng W. (2010) Evaluating China's National Post-Disaster Plans: The 2008 Wenchuan Earthquake's Recovery and Reconstruction Planning. International Journal of Disaster Risk Science 1(2):17-27. doi: 10.3974/j. issn. 2095-0055.2010.02.003 \RTICLt Evaluating.

Di Gregorio L. T, Soares C. A. P (2017) Post-disaster housing recovery guidelines for development countries based on experiences in the American continent. International Journal of Disaster Risk Reduction. Elsevier Ltd, 24(September 2017):340-347. doi: 10.1016/j.ijdrr.2017.06.027.

Griffey A. M (2010) Infrastructure Disaster Management: Insight From Small Business Leaders After A Mega Disaster . Dissertation. University of Phoenix.

Guarnacci U (2012) Governance for sustainable reconstruction after disasters: Lessons from Nias, Indonesia. Environmental Development. Elsevier 2(2012):73-85. doi: 10.1016/j.envdev.2012.03.010.

Guo Y (2012) Urban resilience in post-disaster reconstruction: Towards a resilient development in Sichuan, China. International Journal of Disaster Risk Science 3(1):45-55. doi: 10.1007/s13753-0120006-2. 
Haghani A, Afshar A. M (2010) Development of Advanced Applications Using Bluetooth-Generated Traffic Flow Data 2010 Annual Report Prepared by. Maryland.

Hallegatte S, Dumas P (2009) Can natural disasters have positive consequences? Investigating the role of embodied technical change. Ecological Economics. Elsevier B.V. 68(3):777-786. doi: 10.1016/j.ecolecon.2008.06.011.

Han Z (2014) From Vulnerability To Resilience: Long-Term Livelihood Recovery In Rural China After the 2008 Wenchuan Earthquake. Dissertation. University of Delaware.

Harrowell E, Özerdem A (2019) Understanding the dilemmas of integrating post-disaster and post-conflict reconstruction initiatives: Evidence from Nepal, Sri Lanka and Indonesia. International Journal of Disaster Risk Reduction. Elsevier Ltd 36(February):101092. doi: 10.1016/j.ijdrr.2019.101092.

He F, Zhuang J (2016) Balancing pre-disaster preparedness and post-disaster relief. European Journal of Operational Research. Elsevier B.V. 252(1):246-256. doi: 10.1016/j.ejor.2015.12.048.

He L (2019) Identifying local needs for post-disaster recovery in Nepal. World Development. Elsevier Ltd. 118(June 2019):52-62. doi: 10.1016/j.worlddev.2019.02.005.

Hidayat B, Egbu C (2010) A literature review of the role of project management in post-disaster reconstruction. In: Procs 26th Annual ARCOM Conference. Leeds, UK: Association of Researchers in Construction Management 1269-1278. Available at: http://usir.salford.ac.uk/10144/.

Hinzpeter K, Sandholz S (2018) Squaring the circle? Integrating environment, infrastructure and risk reduction in Post Disaster Needs Assessments. International Journal of Disaster Risk Reduction. Elsevier Ltd 32 (December 2018):113-124. doi: 10.1016/j.ijdrr.2018.05.016.

Howitt R, Okada T, McAneney J, Haynes K, Bird D (2018) Recovering local sociality: Learnings from postdisaster community-scale recoveries. International Journal of Disaster Risk Reduction. Elsevier Ltd 10301042. doi: 10.1016/j.jjdr.2018.08.010.

Hu H, Lei T, Hu J, Zhang S, Kavan P (2018) Disaster-mitigating and general innovative responses to climate disasters: Evidence from modern and historical China. International Journal of Disaster Risk Reduction. Elsevier Ltd 28(June 2018):664-673. doi: 10.1016/j.jjdrr.2018.01.022.

Project Management Institute (2000) PMBOK® guide. 2000th edn, Project Management Institute, Inc. 2000th edn. doi: 10.1093/ajcp/69.5.475.

Ismail D, Taksiah M.A, Roosli R, Samah N.Ab (2014) Project Management Success for Post-disaster Reconstruction Projects: International NGOs Perspectives. Economics and Finance. Elsevier B.V. 120127. doi: 10.1016/s2212-5671(14)00921-6. 
Jigyasu R (2013) Long-term cultural impacts of disaster decision-making: The Case of Post Earthquake Reconstruction in Marathwada, India. International Journal of Architectural Research, 7(3), pp. 14-23. doi: 10.26687/archnet-ijar.v7i3.46.

Han J, Zhang P, Song Y (2019). The Construction of Emergency Management Whole Process Model Based on the Emergency Life-Cycle: Wenchuan Case Study. In: Tan H(ed) Technology for education and learning. Advances in Intelligent and Soft Computing. Poland: Springer 235-243. doi:

10.1017/CB09781107415324.004.

Johnson C (2006) Strategic planning for temporary housing: 1999 earthquakes in Turkey. Dissertation. University of Montreal.

Johnson C, LizarraldeG (2012) Post-disaster housing and reconstruction. International Encyclopedia of Housing and Home. Elsevier, pp. 340-346. doi: 10.1016/B978-0-08-047163-1.00046-1.

Johnson K, Depietri YBreil, M (2016) Multi-hazard risk assessment of two Hong Kong districts. International Journal of Disaster Risk Reduction. Elsevier 19:311-323. doi: 10.1016/j.ijdrr.2016.08.023.

Jordan E (2012) Pathways to community recovery: A qualitative comparative analysis of post-disaster outcomes. Dissertation. University of Colorado.

Kermanshachi S, Bergstrand K, Rouhanizadeh, B (2019) Identifying , Weighting and Causality Modeling of Social and Economic Barriers To Rapid Infrastructure Recovery From Natural Disasters: a Study of Hurricanes Harvey, Irma and Maria. Texas. Available at: www.ctedd.uta.edu.

Kermanshachi S, Rouhanizadeh B. (2018) Feasibility Analysis of Post Disaster Reconstruction Alternatives Using Automated BIM-Based Construction Cost Estimation Tool. Building Tomorrow's Society $1-10$.

Kopaei M. G. (2009) Knowledge Transfer In Post-Disaster Reconstruction: The Problem of Post-postdisaster Reconstruction, ProQuest Dissertations and Theses. McGill University.

Li Q, Umaier K, Koide O (2019) Research on post-Wenchuan earthquake recovery and reconstruction implementation: A case study of housing reconstruction of Dujiangyan City. Progress in Disaster Science. The Author(s). Published by Elsevier Ltd. doi: 10.1016/j.pdisas.2019.100041.

Liao H, Yu J, Wu X, Al-Barakati A, Altalhi A, Herrera F (2019) Life satisfaction evaluation in earthquake-hit area by the probabilistic linguistic GLDS method integrated with the logarithm-multiplicative analytic hierarchy process. International Journal of Disaster Risk Reduction. Elsevier Ltd 38(May):101190. doi: 10.1016/j.jjdr.2019.101190.

Liu L, Lin Y, Wang S. (2014) Urban design for post-earthquake reconstruction: A case study of Wenchuan county, china. Habitat International. Elsevier Ltd 41:290-299. doi: 10.1016/j.habitatint.2013.09.001. 
Liu Z, Han Y (2009) Post-disaster reconstruction and social work development in the Chinese mainland. China Journal of Social Work 2(3):221-223. doi: 10.1080/17525090903211796.

Lizarralde G (2004) Organisational System and Performance of Post-Disaster Reconstruction Projects. Dissertation. Universite de Montreal.

Lu Y, Xu J (2015) Comparative Study on the Key Issues of Postearthquake Recovery and Reconstruction Planning: Lessons from the United States, Japan, Iran, and China. Natural Hazards Review 16(3):04014033-1-11. doi: 10.1061/(asce)nh.1527-6996.0000172.

Meding V.J, Oyedele L, Bruen J (2014) Linking Organisational Competency To Project Success In PostDisaster Reconstruction. Open House International 39(3):7-16.

Moatty A (2017) Post-Flood Recovery: An Opportunity for Disaster Risk Reduction? In: Vinet F (ed) Floods. Elsevier Ltd 350-363. doi: 10.1016/B978-1-78548-269-4.50023-8.

Nejat A, Ghosh S (2016) LASSO Model of Postdisaster Housing Recovery: Case Study of Hurricane Sandy. Natural Hazards Review 17(3):04016007-1-13. doi: 10.1061/(asce)nh.1527-6996.0000223.

Okamoto K, Ishikawa Y (2013) Traditional Wisdom and Modern Knowledge for the Earth's Future. In Noritaka Yagasaki J (ed). International L Geographical Union Kyoto Regional Conference. Kyoto: Springer.

Olshansky R. B (2006) Planning after Hurricane Katrina. Journal of the American Planning Association, 72(2):147-153. doi: 10.1080/01944360608976735.

Opdyke A (2017) Resilient and sustainable infrastructure systems: a comparative analysis of postdisaster shelter coordination, stakeholder participation, and training. ProQuest Dissertations and Theses. University of Colorado Boulder. doi: 10.1108/ijdrbe-10-2017-0060.

Patel S, Hastak M (2013) A framework to construct post-disaster housing. International Journal of Disaster Resilience in the Built Environment 4(1):95-114. doi: 10.1108/17595901311299026.

Ping Xu, Xiaoli Lu, K. Z. and H. Z. (2014) Post-Wenchuan Earthquake Reconstruction and Development in China. In: Kapucu N, Liou K.T (ed) Disaster and Development- Examining Global Issues and Cases. Disaster and Development. New York: Springer. doi: 10.1007/978-3-319-04468-2_25.

Platt S (2018) Factors Affecting the Speed and Quality of Post-Disaster Recovery and Resilience. Earthquake Engineering and Structural Dynamics in Memory of Ragnar Sigbjörnsson. Springer 369-403. doi: https://doi.org/10.1007/978-3-319-62099-2_19.

Powell P. J (2011) Post-disaster reconstruction: A current analysis of Gujarat's response after the 2001 earthquake. Environmental Hazards 10(3):279-292. doi: 10.1080/17477891.2011.597839. 
Rani, W. N. M. W. M, Nifa F.A.B, Ismail M.N, Khalid Kh. N (2017) Planning for post disaster recovery: Lesson learnt from flood events in Kelantan Malaysia. AIP Conference Proceedings. American Institute of Physics 0201431-1-6. doi: 10.1063/1.5005476.

Rehman J, Sohaib O, Asif M, Pradhan B (2019) Applying systems thinking to flood disaster management for a sustainable development. International Journal of Disaster Risk Reduction. Elsevier Ltd 36(February):101101. doi: 10.1016/j.ijdrr.2019.101101.

Robert O, Ikuo K, Kazuyoshi O. (2005) The Kobe Earthquake, Ten Years Later. Planning 71(9):36. Available at: http://search.ebscohost.com/login.aspx?direct=true\&db=buh\&AN=18483701\&site=ehost-live.

Robert Olshansky (2002) Planning for disasters. Journal of the American Planning Association, 68(4):453.

Rose A (2011) Resilience and sustainability in the face of disasters. Environmental Innovation and Societal Transitions. Elsevier 1(1):96-100. doi: 10.1016/j.eist.2011.04.003.

Rouhanizadeh B, Kermanshachi Sh, Dhamangaonkar V.S (2013) Reconstruction of Critical and Interdependent Infrastructures due to Catastrophic Natural Disasters: Lessons Learned. Perspektif Pelajar Terhadap Kurikulum Sejarah Peringkat Menengah di Malaysia 1727.

Rouhanizadeh B, Bergstrand S (2019a) Comparative Analysis of Public's and Decision-Maker's Perspectives on Socioeconomic Barriers Causing Delay in Post-disaster Recovery Processes. in ASCE Construction Research Congress (CRC) 1-10.

Rouhanizadeh, B, Bergstrand S (2019b) Investigating the Relationships of Socioeconomic Factors Delaying Post-Disaster Reconstruction. ASCE International Conference on Computing in Civil Engineering 16-24. doi: 10.6224/JN.59.5.16.

Sadiqi Z, Trigunarsyah B Coffey V (2017) A framework for community participation in post-disaster housing reconstruction projects: A case of Afghanistan. International Journal of Project Management. Elsevier Ltd APM and IPMA, 35(5):900-912. doi: 10.1016/j.ijproman.2016.11.008.

Supernaw A.S (2019) Impact of Project Management Methodology Use in Post-Disaster Recovery and Mitigation Projects Dissertation. Northcentral University.

Silva J.D (2010) Lessons from Aceh. Key Considerations in Post-Disaster Reconstruction, Post-Disaster Reconstruction: Lessons from Aceh. Practical Action Publishing. doi: 10.4324/9781849775137.

Siriwardhana C, Hewage S, Deshabandu R, Siribaddana S, Sumathipala A (2012) Psychosocial and Ethical Response to Disasters: A SWOT Analysis of Post-Tsunami Disaster Management in Sri Lanka. Asian Bioethics Review 171-182. doi: 10.1353/asb.2012.0027. 
Tanwattana P (2018) Systematizing Community-Based Disaster Risk Management (CBDRM): Case of urban flood-prone community in Thailand upstream area. International Journal of Disaster Risk Reduction. Elsevier Ltd 28(June 2018):798-812. doi: 10.1016/j.ijdrr.2018.02.010.

Tran T. A (2015) Post-disaster housing reconstruction as a significant opportunity to building disaster resilience: a case in Vietnam. Natural Hazards 61-79. doi: 10.1007/s11069-015-1826-3.

Vahanvati M, Mulligan M (2017) A new model for effective post-disaster housing reconstruction: Lessons from Gujarat and Bihar in India. International Journal of Project Management. Elsevier Ltd APM and IPMA 35(5): 802-817. doi: 10.1016/j.jproman.2017.02.002.

Wu J. I. E. Y (2003) a Comparative Study of Housing Reconstruction After Two Major Earthquakes: the 1994 Northridge Earthquake in the United States and the 1999 Chi-Chi Earthquake in Taiwan, ProQuest Dissertations and Theses. Texas A\&M University.

Xiao Y, Olshansky R, Zhang Y, Johnson L.A, Song Y (2019) Financing rapid community reconstruction after catastrophic disaster: lessons from the 2008 Wenchuan earthquake in China. Natural Hazards. Springer Netherlands (0123456789). doi: 10.1007/s11069-019-03789-9.

Xu H, Wang L, Li Y, Huang L, Yin, L (2019) Critical Chinese government behavior for swift housing reconstruction programme - The case of Dujiangyan following Wenchuan Earthquake. International Journal of Disaster Risk Reduction. Elsevier Ltd. doi: 10.1016/j.ijdrr.2019.101307.

Xu J, Lu Y (2012) Meta-synthesis pattern of post-disaster recovery and reconstruction: Based on actual investigation on 2008 Wenchuan earthquake. Natural Hazards 60(2):199-222. doi: 10.1007/s11069-0110003-6.

Xu J, Lu Y (2018) Towards an earthquake-resilient world: from post-disaster reconstruction to pre-disaster prevention. Environmental Hazards 269-275. doi: 10.1080/17477891.2018.1500878.

Yang B (2011) A Comprehensive Study Of The Chinese Government' S Natural Disaster Communication Framework Based On The Natural Disaster Management And Communication System's Response To Two Natural Disasters. Dissertation. University of Southern California.

Zhang Y, Peacock W. G (2010) Planning for Housing recovery? Lessons learned from Hurricane Andrew. Journal of the American Planning Association 76(1):5-24. doi: 10.4324/9781351203319-13.

Zhao B, Taucer F, Rossetto T (2009) Field investigation on the performance of building structures during the 12 May 2008 Wenchuan earthquake in China. Engineering Structures. Elsevier Ltd 31(8):1707-1723. doi: 10.1016/j.engstruct.2009.02.039.

\section{Figures}




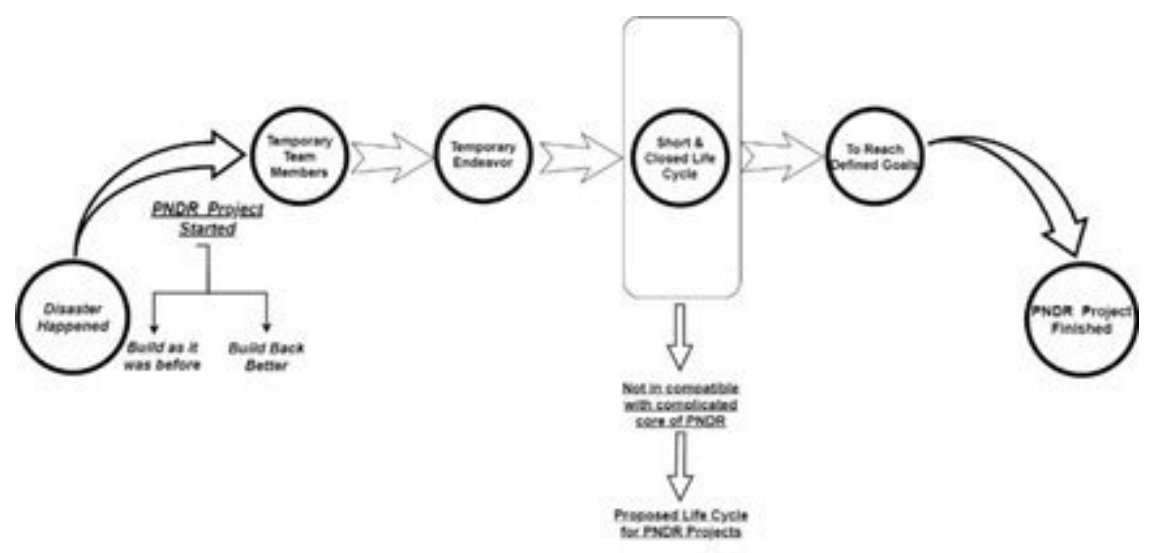

\section{Figure 1}

Widely applied linear process for the PNDR projects

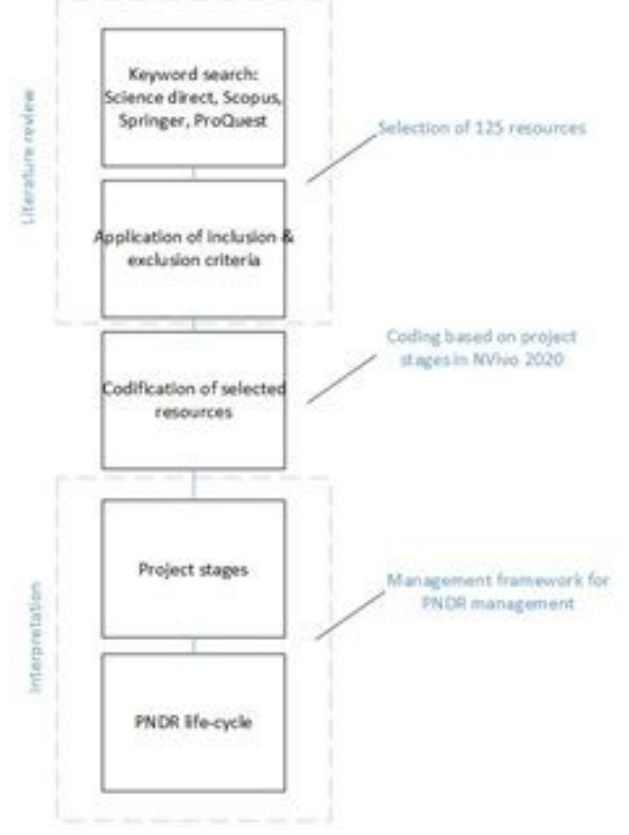

Figure 2

Research methodology 


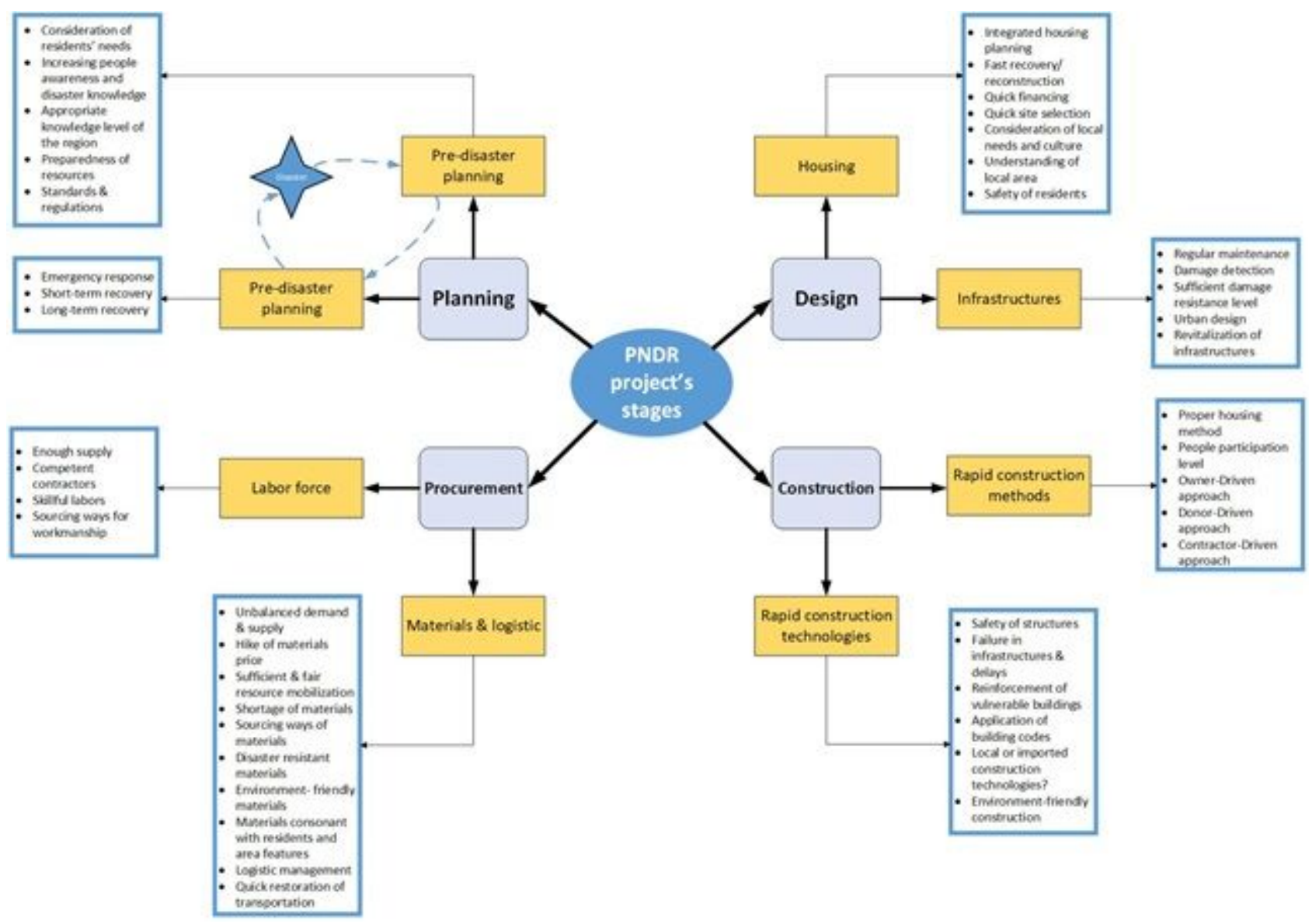

\section{Figure 3}

Project management stages of PNDR projects

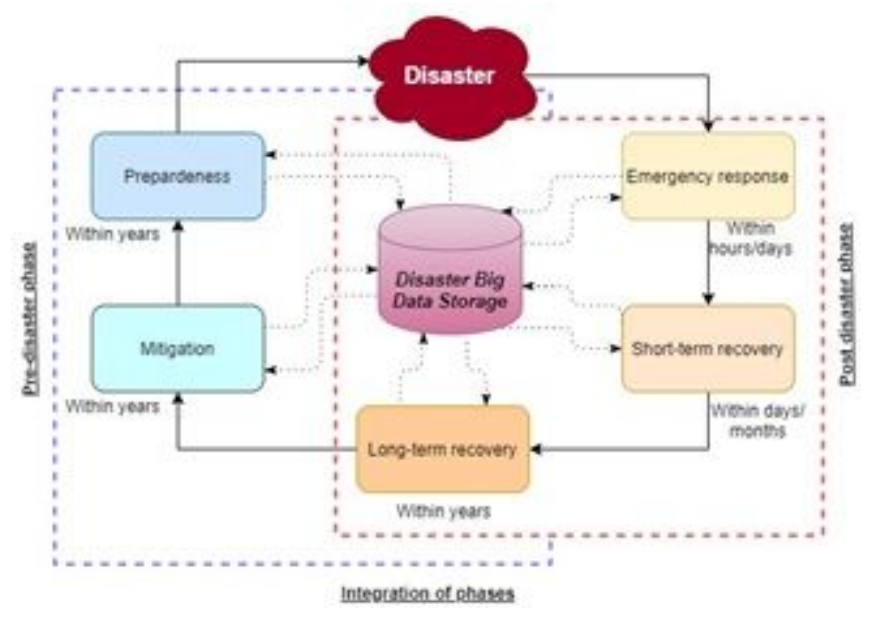

Figure 4

Life-cycle of natural disaster recovery projects 


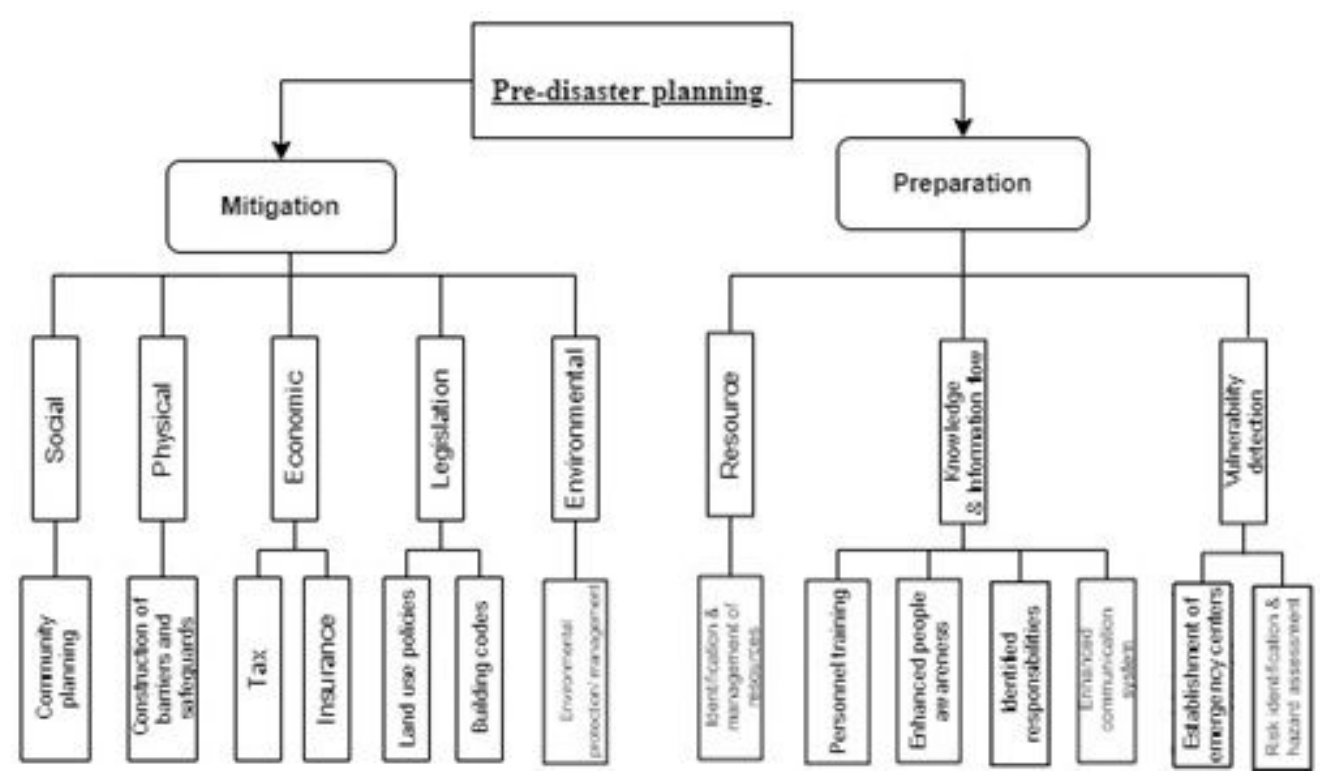

Figure 5

Planned activities and phases of pre-disaster stage

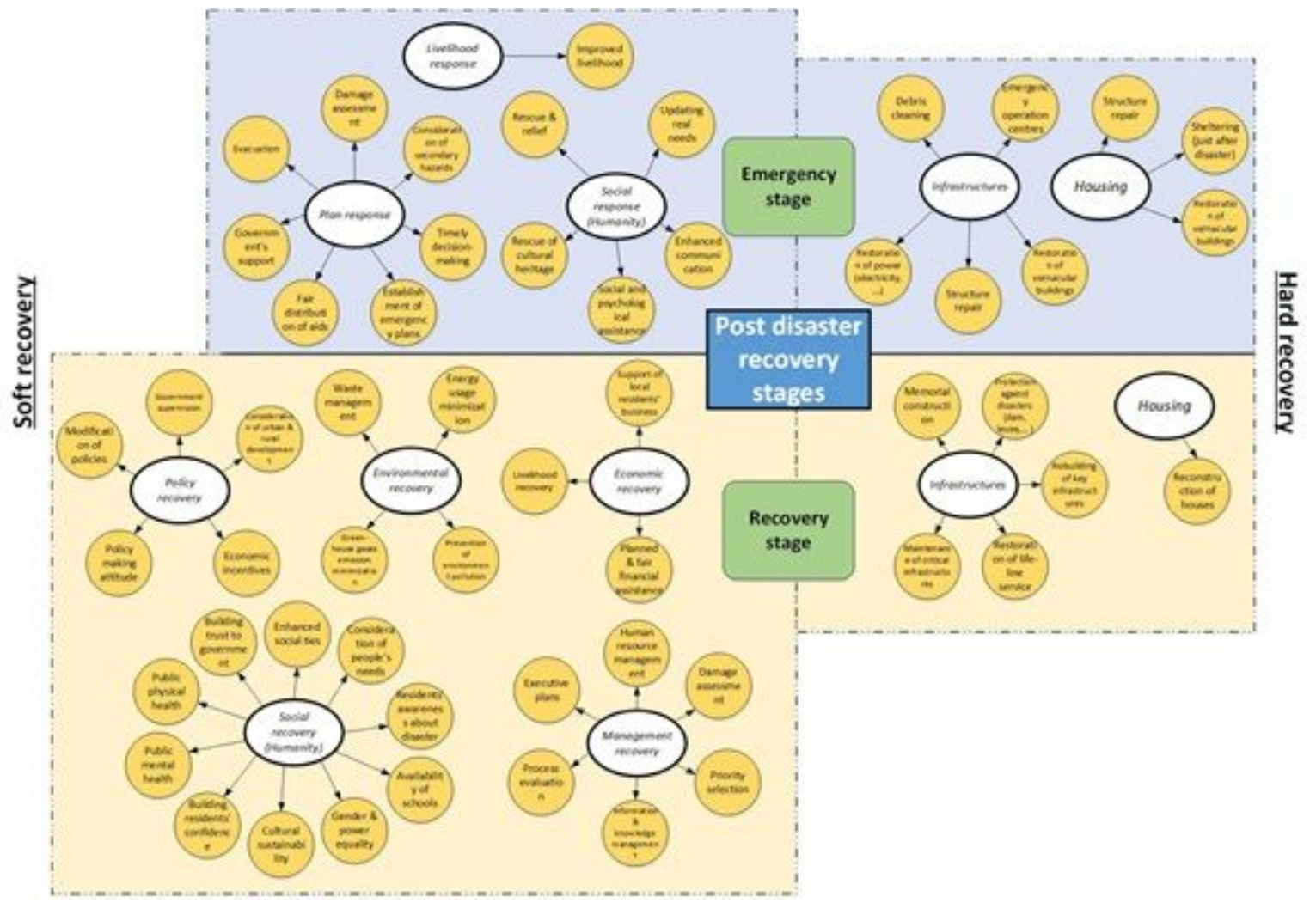

Figure 6

Planned activities and phases of the post-disaster recovery stage 


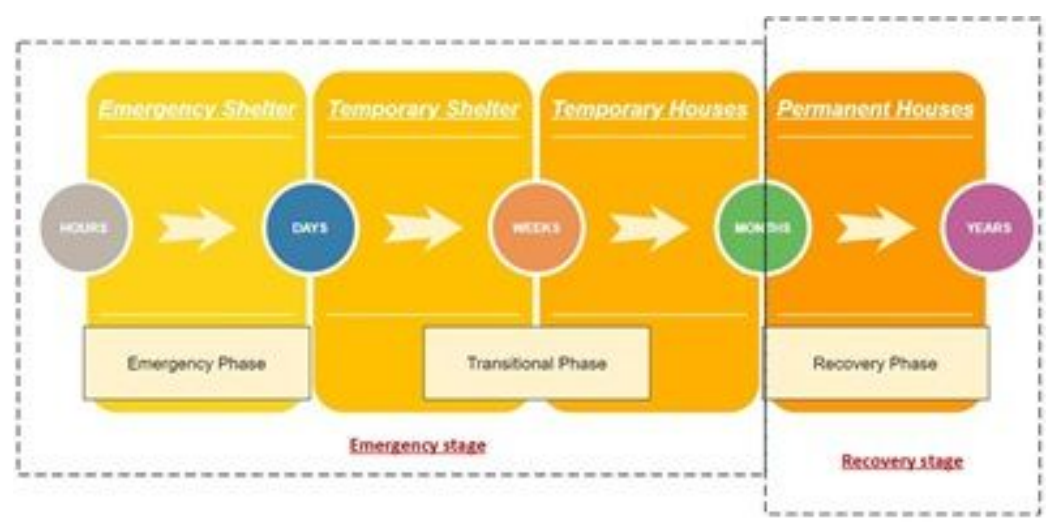

Figure 7

Time-based stages of housing

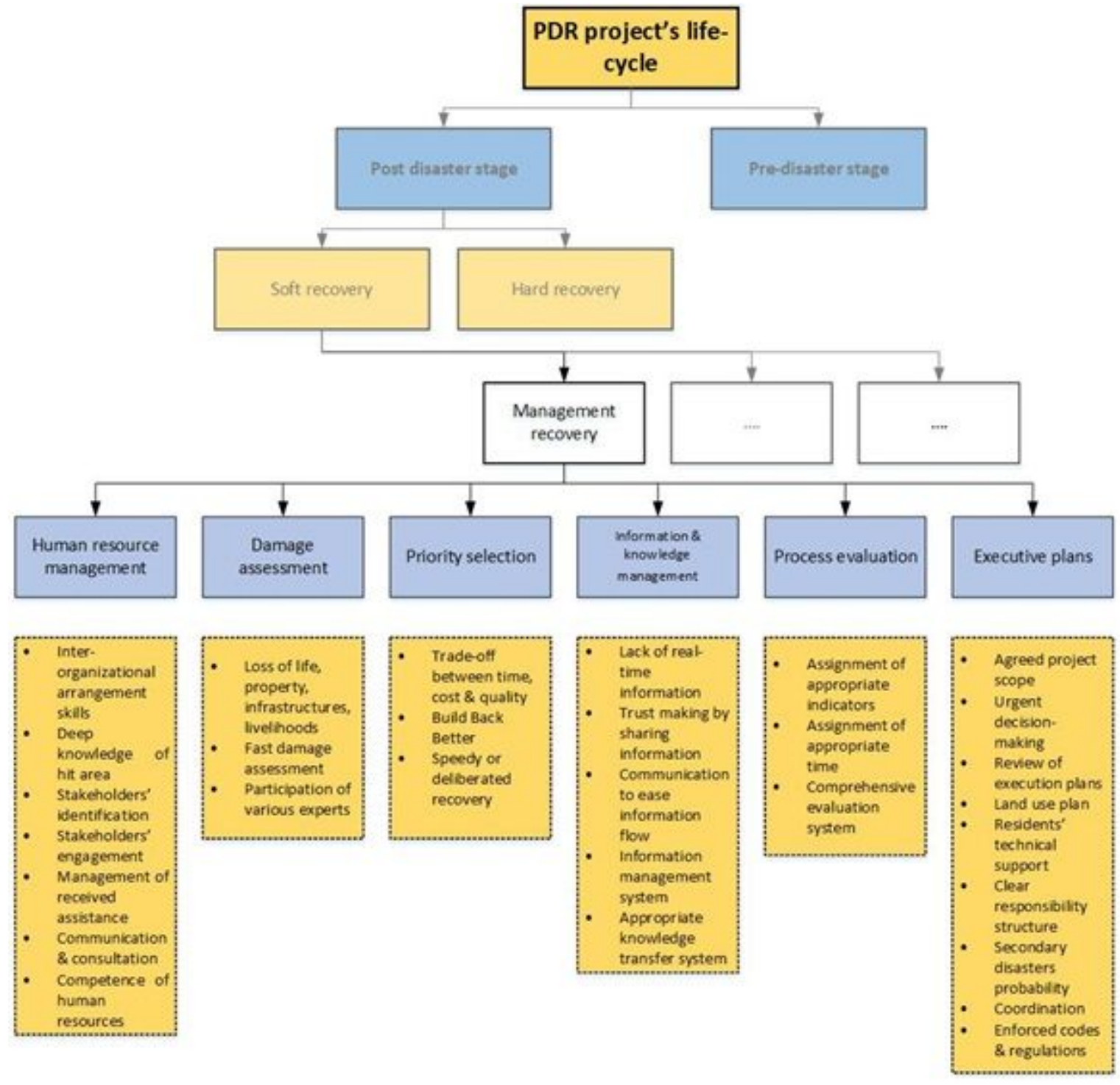

Figure 8

Management recovery activities 

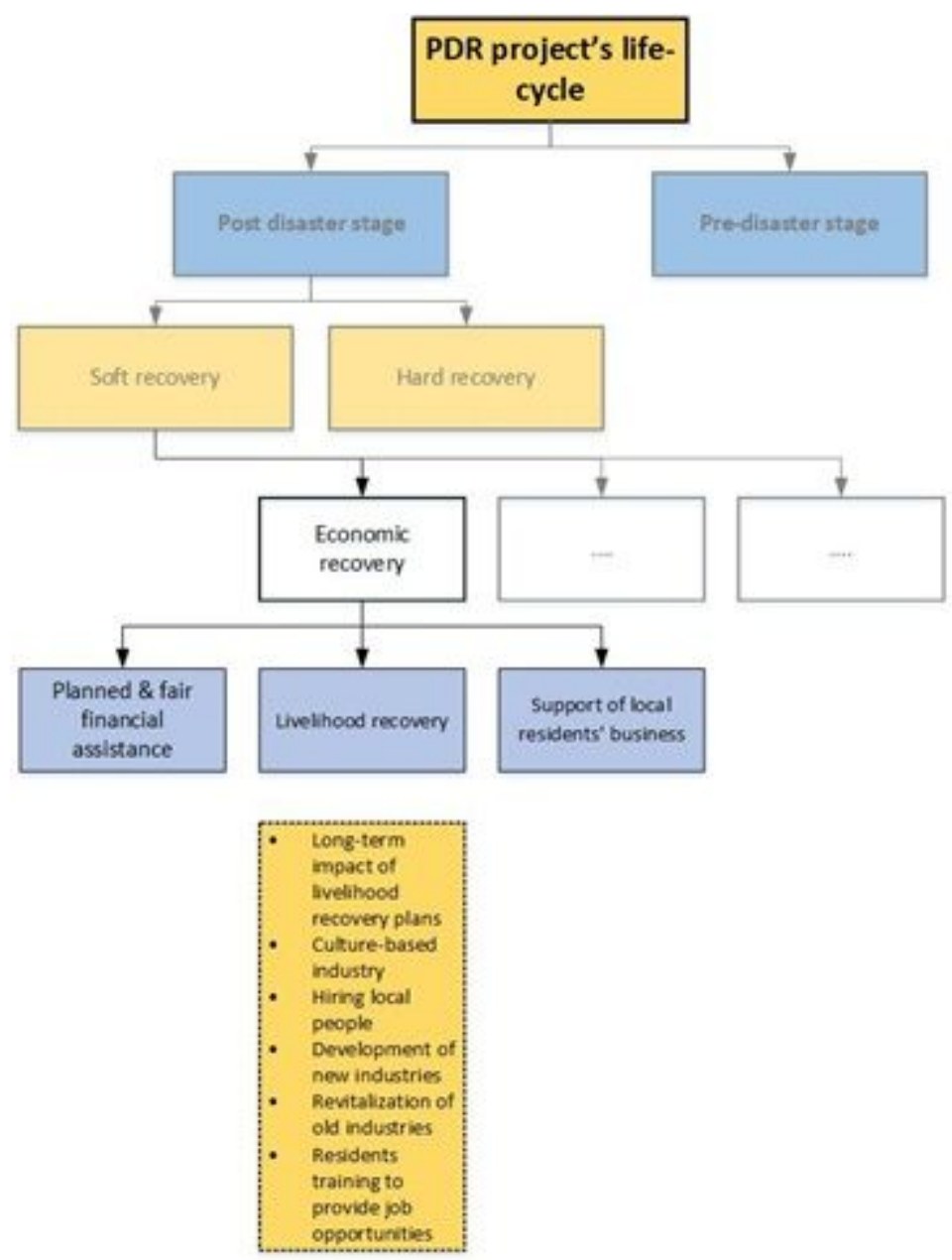

Figure 9

Economic recovery activities 


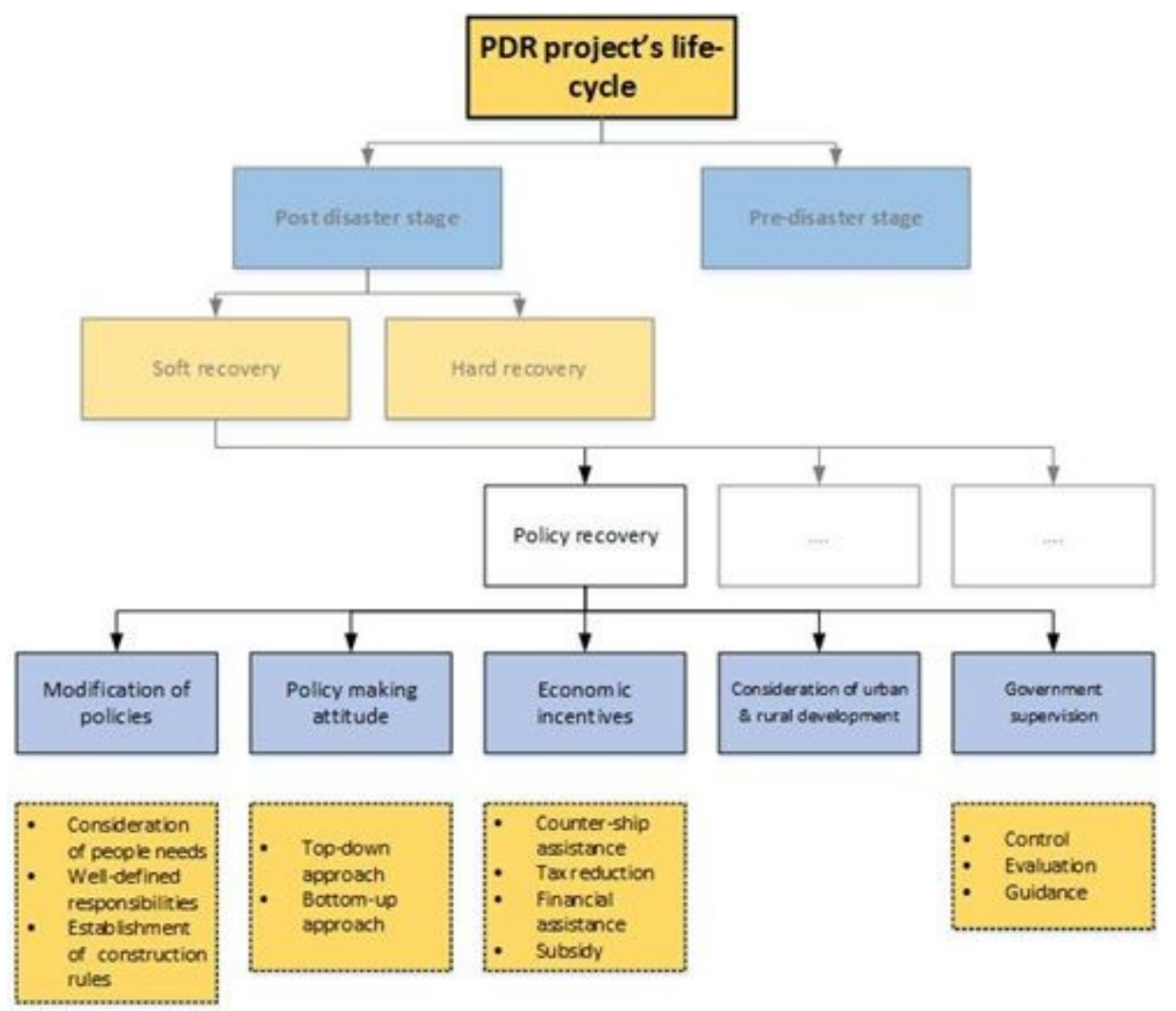

Figure 10

Policy recovery activities

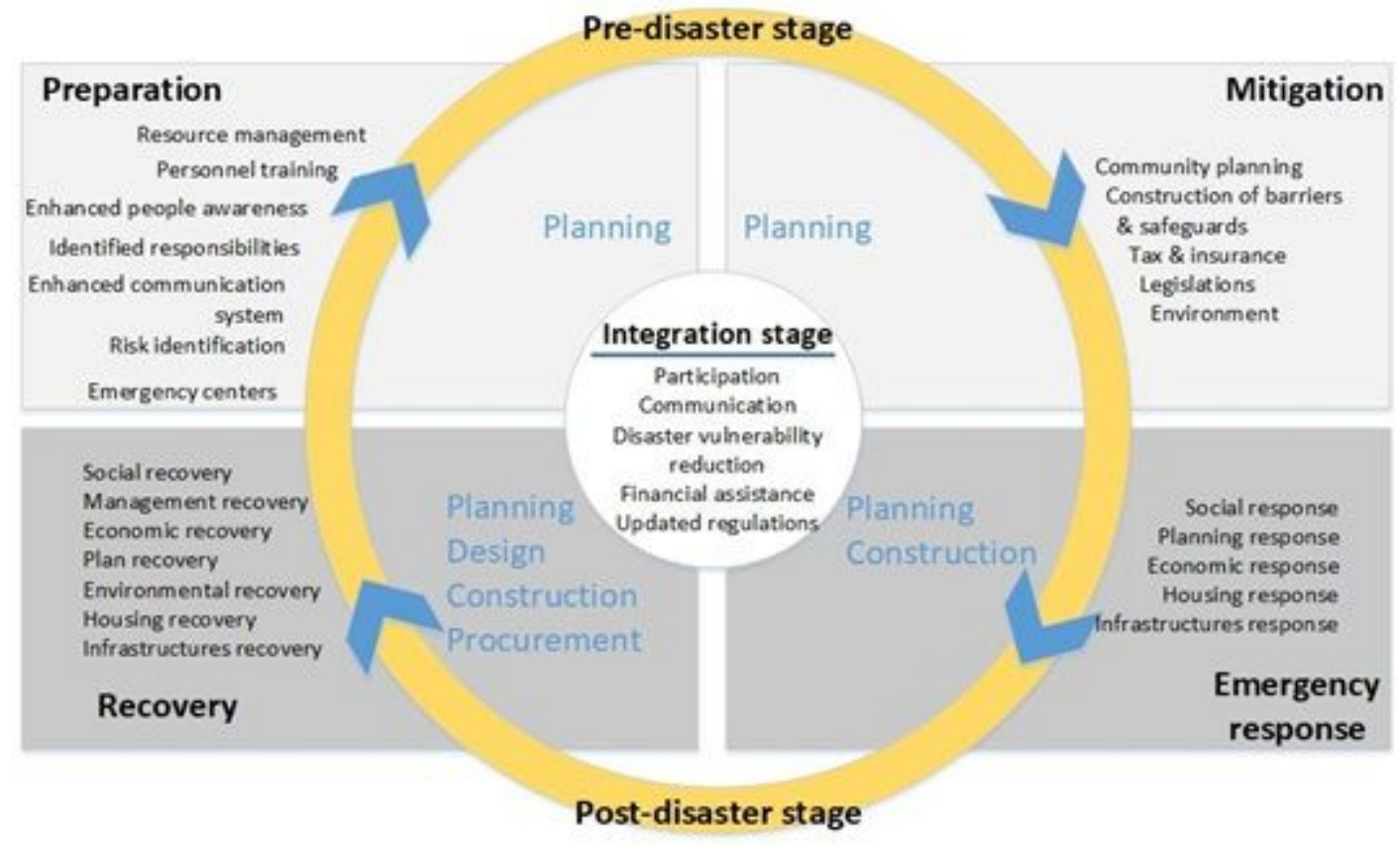

Figure 11

Conceptual framework for management of PNDR projects 